\title{
Use of insulin pump therapy in children and adolescents with type 1 diabetes and its impact on metabolic control: comparison of results from three large, transatlantic paediatric registries
}

\author{
Jennifer L. Sherr ${ }^{1} \cdot$ Julia M. Hermann ${ }^{2} \cdot$ Fiona Campbell $^{3} \cdot$ Nicole C. Foster $^{4}$. \\ Sabine E. Hofer ${ }^{5}$. Jeremy Allgrove ${ }^{6} \cdot$ David M. Maahs $^{7} \cdot$ Thomas M. Kapellen $^{8}$. \\ Naomi Holman' ${ }^{9}$. William V. Tamborlane ${ }^{1} \cdot$ Reinhard W. Holl ${ }^{2} \cdot$ Roy W. Beck ${ }^{4}$. \\ Justin T. Warner ${ }^{10}$ • for the T1D Exchange Clinic Network, the DPV Initiative, \\ and the National Paediatric Diabetes Audit and the Royal College of Paediatrics \\ and Child Health registries
}

Received: 26 June 2015 / Accepted: 29 September 2015 / Published online: 7 November 2015

(C) Springer-Verlag Berlin Heidelberg 2015

\begin{abstract}
Aims/hypothesis While the use of insulin pumps in paediatrics has expanded dramatically, there is still considerable variability among countries in the use of pump technology. The present study sought to describe differences in metabolic control and pump use in young people with type 1 diabetes using data collected in three multicentre registries.

Methods Data for the years 2011 and 2012 from 54,410 children and adolescents were collected from the Prospective Diabetes Follow-up Registry (DPV; $n=26,198$ ), T1D Exchange (T1DX; $n=13,755)$ and the National Paediatric Diabetes Audit (NPDA; $n=14,457)$. The modality of insulin delivery, based on age, sex and ethnic minority status, and the impact of pump use on $\mathrm{HbA}_{1 \mathrm{c}}$ levels were compared.
\end{abstract}

Electronic supplementary material The online version of this article (doi:10.1007/s00125-015-3790-6) contains peer-reviewed but unedited supplementary material, which is available to authorised users.

Nicole C. Foster

t1DStats@jaeb.org

1 Pediatric Endocrinology, Children's Diabetes Program, Yale School of Medicine, New Haven, CT, USA

2 ZIBMT, Institute of Epidemiology and Medical Biometry, University of Ulm, Ulm, Germany; affiliated with the German Center for Diabetes Research (DZD),

http://www.dzd-ev.de

3 General Paediatrics and Diabetes, Leeds Children's Hospital, Leeds, UK

4 Jaeb Center for Health Research, 15310 Amberly Drive, Suite 350, Tampa, FL 33647, USA
Results The overall mean $\mathrm{HbA}_{1 \mathrm{c}}$ level was higher in the NPDA $(8.9 \pm 1.6 \%[74 \pm 17.5 \mathrm{mmol} / \mathrm{mol}])$ than in the DPV $(8.0 \pm 1.6 \%[64 \pm 17.0 \mathrm{mmol} / \mathrm{mol}], p<0.001)$ and T1DX $(8.3 \pm 1.4 \%$ [68 $\pm 15.4 \mathrm{mmol} / \mathrm{mol}], p<0.001)$. Conversely, pump use was much lower in the NPDA (14\%) than in the DPV $(41 \%, p<0.001)$ and T1DX $(47 \%, p<0.001)$. In a pooled analysis, pump use was associated with a lower mean $\mathrm{HbA}_{1 \mathrm{c}}$ (pump: $8.0 \pm 1.2 \%$ [64 $\left.\pm 13.3 \mathrm{mmol} / \mathrm{mol}\right]$ vs injection: $8.5 \pm 1.7 \%[69 \pm 18.7 \mathrm{mmol} / \mathrm{mol}], p<0.001)$. In all three registries, those with an ethnic minority status were less likely to be treated with a pump $(p<0.001)$ and boys were treated with a pump less often compared with girls $(p<0.001)$.

Conclusions/interpretation Despite similar clinical characteristics and proportion of minority participants, substantial

5 Department of Paediatrics, Medical University of Innsbruck, Innsbruck, Austria

6 Department of Paediatric Endocrinology and Diabetes, Royal London Children's Hospital, Barts Health NHS Trust, London, UK

7 Barbara Davis Center for Childhood Diabetes, Aurora, CO, USA

8 Department of Endocrinology and Diabetology, University of Leipzig, Hospital for Children and Adolescents, Leipzig, Germany

9 Institute of Cardiovascular and Medical Sciences, University of Glasgow, Glasgow, UK

10 Paediatric Endocrinology and Diabetes, Children's Hospital for Wales, Cardiff, UK 
differences in metabolic control exist across the three large transatlantic registries of paediatric patients with type 1 diabetes, which appears to be due in part to the frequency of insulin pump therapy.

Keywords Clinical outcomes · Continuous subcutaneous insulin infusion · DPV · Insulin pumps · National Paediatric Diabetes Audit · T1D Exchange clinic registry · Treatment modalities - Type 1 diabetes

$\begin{array}{ll}\text { Abbreviations } \\ \text { T1DX } & \text { T1D Exchange } \\ \text { DPV } & \text { Prospective Diabetes Follow-up Registry } \\ \text { NPDA } & \text { National Paediatric Diabetes Audit } \\ \text { NICE } & \text { National Institute for Health and Care Excellence } \\ \text { SES } & \text { Socioeconomic status }\end{array}$

\section{Introduction}

Despite the introduction of continuous subcutaneous insulin infusion pump therapy $\sim 35$ years ago [1], widespread translation of this technology into paediatric practice has only occurred in the last 15 years. Increased use of pumps in paediatric medicine has been driven by advancements in pump technology and recognition of the importance of lowering $\mathrm{HbA}_{1 \mathrm{c}}$ levels to delay or prevent the vascular complications of diabetes [2]. Small paediatric trials of pump therapy have shown that pump use is associated with lower $\mathrm{HbA}_{1 \mathrm{c}}$ levels, reduced hypoglycaemia and no concomitant rise in the prevalence of overweight/obesity [3]. A recent large 7 year case-control study corroborated these findings by showing that pump therapy was associated with long-term lowering of $\mathrm{HbA}_{1 \mathrm{c}}$ levels [4].

In 2007, a joint consensus statement by leading paediatric diabetologists recommended that pump therapy should be considered in children and adolescents with suboptimal diabetes control, wide fluctuations in blood glucose levels regardless of $\mathrm{HbA}_{1 \mathrm{c}}$ and when the insulin regimen compromised lifestyle: indications for pump use that could be met by almost every young person with type 1 diabetes [5]. Nevertheless, variations in the support for and use of pump technology exist, even among developed Western countries. To address this issue, we compared data from three large registries of paediatric type 1 diabetes patients: the German/Austrian Prospective Diabetes Follow-up Registry (DPV), the US T1D Exchange (T1DX) and the English/Welsh National Paediatric Diabetes Audit (NPDA). We examined differences between the registries in frequency of pump therapy based on age, sex and ethnic minority status, as well as the impact of pump use on $\mathrm{HbA}_{1 \mathrm{c}}$ levels.

\section{Methods}

Participants Participants in all three registries were included in the analysis if they had a history of type 1 diabetes, were aged $<18$ years, information was available on the insulin delivery modality, and they attended at least one office visit during 2011-2012, as reported previously [6]. Sites for DPV and T1DX are listed in the electronic supplementary material (ESM) List of registry sites.

The DPV cohort included 26,198 participants from 209 sites. Since the clinical characteristics and patterns of pump use were similar in Germany and Austria, data from both countries were combined for analysis. The T1DX cohort included 13,755 children and adolescents enrolled between September 2010 and August 2012 at one of the 57 registry sites that care for paediatric patients. NPDA data were collected between April 2011 and March 2012 for 14,457 participants. As for the DPV, data from both England and Wales were combined for these analyses.

Explanatory variables The median Diabetes Control and Complications Trial standardised $\mathrm{HbA}_{1 \mathrm{c}}$ level (i.e. presented as a percentage), excluding any values obtained within 3 months of diagnosis, was computed for each participant [7]. Any use of a pump in the past year was categorised as pump use. Definitions of ethnic status for each registry were described previously [6].

Statistical methods Summary statistics were calculated within registries and overall. Kruskal-Wallis or $\chi^{2}$ tests were performed to compare demographic and clinical characteristics among registries. The proportions of participants using pump therapy were tabulated by registry and by strata of explanatory variable. These analyses were repeated with multivariable logistic regression models, adjusting for age, diabetes duration, sex and ethnicity, to compare the rates of pump use between registries. Multivariable linear regression models were used to compare $\mathrm{HbA}_{1 \mathrm{c}}$ values among registries and between pump and injection users. Additional analyses were stratified by sex, age group and minority status. Statistical analyses were performed using SAS statistical software (version 9.4, SAS Institute, Cary, NC, USA). All $p$ values are two-sided. A priori, in view of the large sample size and multiple comparisons, only $p$ values $<0.01$ were considered statistically significant. 


\section{Results}

Demographic data are presented in Table 1. The threefold greater use of insulin pumps in the DPV and T1DX registries compared with the NPDA was the most striking difference $(p<0.001)$.

The mean unadjusted $\mathrm{HbA}_{1 \mathrm{c}}$ level was higher in NPDA $(8.9 \pm 1.6 \%[74 \pm 17.5 \mathrm{mmol} / \mathrm{mol}])$ vs DPV $(8.0 \pm 1.6 \%[64 \pm$ $17.0 \mathrm{mmol} / \mathrm{mol}], p<0.001)$ and T1DX $(8.3 \pm 1.4 \%[68 \pm$ $15.4 \mathrm{mmol} / \mathrm{mol}], p<0.001$; Fig. 1). Elevated $\mathrm{HbA}_{1 \mathrm{c}}$ levels in NPDA were primarily due to higher $\mathrm{HbA}_{1 \mathrm{c}}$ values in injection patients $(9.0 \pm 0.4 \%[75 \pm 4.4 \mathrm{mmol} / \mathrm{mol}])$ compared with T1DX $(8.5 \pm 0.4 \%[69 \pm 4.4 \mathrm{mmol} / \mathrm{mol}], p<0.001)$ and DPV $(8.1 \pm 0.4 \%[65 \pm 4.4 \mathrm{mmol} / \mathrm{mol}], p<0.001)$. In all three registries combined, unadjusted $\mathrm{HbA}_{1 \mathrm{c}}$ levels in insulin pump users $(8.0 \pm 1.2 \%[64 \pm 13.3 \mathrm{mmol} / \mathrm{mol}])$ were significantly lower than in injection users $(8.5 \pm 1.7 \%[69 \pm 18.7 \mathrm{mmol} /$ $\mathrm{mol}], p<0.001$ ).

The frequency of pump use differed by age across the three registries (ESM Fig. 1). In the DPV, $\sim 70 \%$ of children aged $<6$ years vs $35-40 \%$ of older participants received insulin pump therapy. In the T1DX, the lowest rate of pump use was seen in the youngest cohort; in contrast, low rates of pump use were observed in all age groups in the NPDA (ESM Fig. 1).

Across all three registries, $22.1 \%$ of ethnic minority participants used pumps vs $34.5 \%$ of non-ethnic minority patients (OR 0.54 [95\% CI 0.52, 0.57], $p<0.001$; ESM Fig. 2) even after adjustment for age, duration of diabetes, sex and registry (DPV, OR 0.62 [95\% CI 0.58, 0.66]; T1DX, OR 0.40 [95\% CI $0.37,0.44]$; NPDA, OR 0.50 [ $95 \%$ CI $0.45,0.58]$ ). Girls had a higher likelihood of being on pump therapy compared with boys (OR 1.22 [95\% CI 1.17, 1.27]).

\section{Discussion}

In 54,410 children and adolescents with type 1 diabetes in three registries, $\mathrm{HbA}_{1 \mathrm{c}}$ levels were on average $0.5 \%$ $(5.5 \mathrm{mmol} / \mathrm{mol})$ lower in participants receiving insulin pump vs injection therapy, a finding similar to that reported in a number of small, single-centre studies. However, $<50 \%$ of young people in these five countries were receiving pump therapy. Pump use was limited even though the majority of participants had $\mathrm{HbA}_{1 \mathrm{c}}$ levels that exceeded the glycaemic goal of $\mathrm{HbA}_{1 \mathrm{c}}(<7.5 \%$ [ $\left.<58 \mathrm{mmol} / \mathrm{mol}]\right)$ recommended for children and adolescents with diabetes [8-10].

The use of pump therapy in NPDA was only $\sim 30 \%$ of that in the DPV and T1DX registries, which could partially be related to national UK guidance from the National Institute for Health Care and Excellence (NICE) specifying that pumps should be considered for children $<12$ years of age provided that multiple daily injection therapy is considered impractical or inappropriate. Moreover, the use of pump therapy in patients aged $>12$ years is only recommended if an individual has disabling hypoglycaemia or if $\mathrm{HbA}_{1 \mathrm{c}}$ has remained high $(>8.5 \%$ [ $>69 \mathrm{mmol} / \mathrm{mol}])$ on injection therapy [11]. These limitations do not exist in the other countries. The rates of pump use by age differed between the registries. The youngest age group had the highest frequency of pump use in both the DPV and NPDA registries. Conversely, adolescents had the highest frequency of pump use in the T1DX, which may provide greater independence and autonomy and facilitate the transition of care that begins in adolescence.

Despite the presence of many similar clinical characteristics for participants in the three registries, the overall $\mathrm{HbA}_{1 \mathrm{c}}$ level was highest in the NPDA. This difference was not entirely explained by differences in pump use in the NPDA cohort because $\mathrm{HbA}_{1 \mathrm{c}}$ was higher in injection-treated and pump-treated patients in the NPDA compared with the other two registries. The difference in $\mathrm{HbA}_{1 \mathrm{c}}$ levels between injection-treated and pump-treated participants was greatest in the NPDA and smallest in the DPV.

The use of insulin pump therapy was lower in ethnic minorities in all three registries. As ethnic minority background and low socioeconomic status (SES) are often inter-related, it is possible that this relationship resulted from low SES rather than racial/ethnic factors.

Table 1 Participant characteristics by registry

\begin{tabular}{|c|c|c|c|c|}
\hline Characteristic & $\operatorname{DPV}(n=26,198)$ & $\operatorname{T1DX}(n=13,755)$ & NPDA $(n=14,457)$ & $p$ value \\
\hline Sex, $\%$ male & 53 & 52 & 53 & 0.10 \\
\hline Age (y), median (IQR) & $12.1(8.6-14.8)$ & $12.2(9.2-15.0)$ & $12.9(9.9-15.0)$ & $<0.001$ \\
\hline Duration of diabetes (y), median (IQR) & $2.9(0.3-6.1)$ & $3.0(1.0-6.0)$ & $4.1(1.8-7.0)$ & $<0.0001$ \\
\hline $\mathrm{HbA}_{1 \mathrm{c}}(\%)$, mean $\pm \mathrm{SD}$ & $8.0 \pm 1.6$ & $8.3 \pm 1.4$ & $8.9 \pm 1.6$ & $<0.001$ \\
\hline $\mathrm{HbA}_{1 \mathrm{c}}(\mathrm{mmol} / \mathrm{mol})$, mean $\pm \mathrm{SD}$ & $64 \pm 17.0$ & $68 \pm 15.4$ & $74 \pm 17.5$ & \\
\hline On pump therapy $(\%)$ & 41 & 47 & 14 & $<0.001$ \\
\hline Ethnic minority status (\%) & 20 & 22 & 24 & $<0.001$ \\
\hline
\end{tabular}

IQR, interquartile range; y, years 

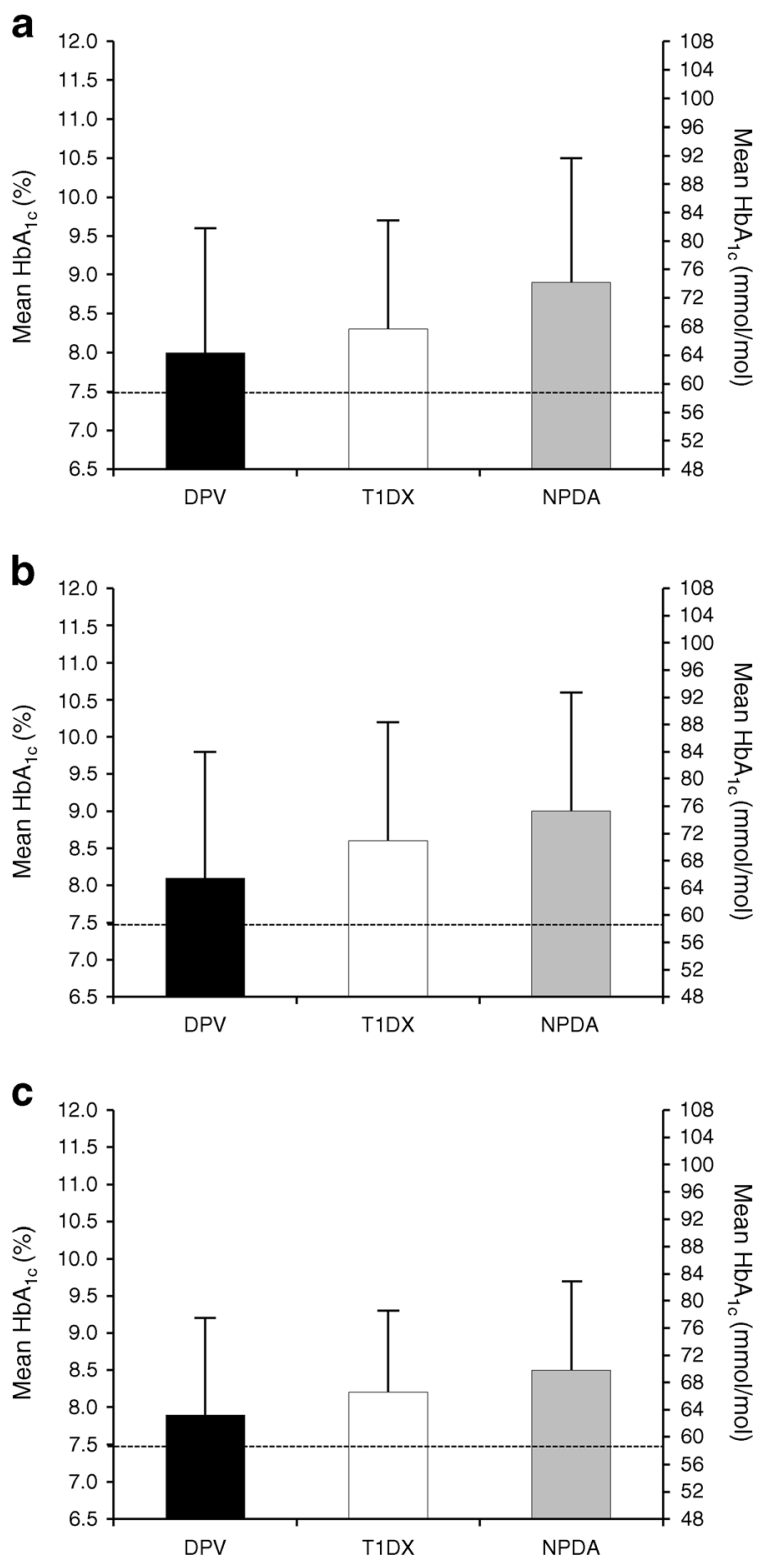

Fig. 1 The overall mean $\mathrm{HbA}_{1 \mathrm{c}}$ (a), mean $\mathrm{HbA}_{1 \mathrm{c}}$ in participants using injection therapy (b) and mean $\mathrm{HbA}_{1 \mathrm{c}}$ in participants using pump therapy (c) by registry. Dashed lines represent an $\mathrm{HbA}_{1 \mathrm{c}}$ of $7.5 \%(58.5 \mathrm{mmol} /$ $\mathrm{mol}$ ), the glycaemic target recommended for the paediatric population

Future investigations should focus on the reasons for the lower use of pumps in children and adolescents of ethnic minorities and advocacy efforts should be directed at assuring that all young people with type 1 diabetes have equal access to this insulin delivery modality, when appropriate. As pre-screening of individuals deemed suitable for pump therapy is often conducted by the clinical care team, those who are provided with the option of this insulin delivery modality frequently have more consistent follow-up and display better adherence to the prescribed medical regimen. Methods to motivate and encourage patients who are struggling or disengaged with their care need to be explored.
A limitation of the present study is that the period of pump use was not reported. It is possible that someone new to pump therapy may not have fully realised the benefits of pump therapy, which would have mitigated our ability to detect differences in metabolic control. Additionally, the present analysis included those within the first year after diagnosis; thus, it is possible that endogenous residual insulin production could have led to lower $\mathrm{HbA}_{1 \mathrm{c}}$ levels in those with the shortest disease duration. Interestingly, regardless of disease duration ( $<2$ years or $>2$ years), the use of insulin pumps was associated with lower $\mathrm{HbA}_{1 \mathrm{c}}$ levels across all three registries (ESM Table 1). In contrast to the other two population-based registries, all T1DX participants received their care at specialised, tertiary care centres. In addition, the mode of insulin delivery was submitted for only $\sim 60 \%$ of patients in the NPDA.

It is important to note that the cross-sectional data reported in this paper primarily reflect the evolution of insulin pump therapy in paediatric care over the past 15 years rather than the current revolution in diabetes technology that is just beginning to be translated into better care for children with type 1 diabetes. As science and technology move closer to a mechanical solution to the problems of managing children and adolescents with type 1 diabetes, it will be even more important to ensure that our paediatric patients have access to such treatment advancements.

Acknowledgements We wish to thank the thousands of patients and their families who contributed to these registries/audits, as well as the numerous investigators.

Funding The T1DX is supported through the Leona M. and Harry B. Helmsley Charitable Trust. The DPV is supported through the German BMBF Competence Network Diabetes Mellitus (FKZ 01GI1106), which was integrated into the DZD as of January 2015. The NPDA is commissioned by the Healthcare Quality Improvement Partnership and delivered by the Royal College of Paediatrics and Child Health.

Duality of interest statement JMH, FC, JA, NCF, NH and JTW have no conflict of interest to report. JLS's non-profit employer has received research funding from Medtronic with no personal compensation to JLS. SEH has received payments for lectures from Lilly and Roche. DMM is on the advisory board for Insulet and his non-profit employer has received research funding from Medtronic and Dexcom. TMK has received payments for lectures (including service on speaker's bureaus) from Roche and Medtronic. WVT has received consultancy payments from Novo Nordisk, Sanofi and Medtronic. RWH's non-profit employer has received grants or has grants pending from Sanofi for research in type 2 diabetes and from Medtronic Switzerland for research on in-patient care. RWB's non-profit employer has received consultant payments on his behalf from Sanofi and Animas and a research grant from NovoNordisk with no personal compensation to RWB.

Contribution statement JLS researched data and wrote/edited the manuscript; JMH researched data, performed statistical analyses and wrote/edited the manuscript; NCF researched data and wrote/edited the manuscript; and FC, SEH, JA, DMM, TMK, NH, WVT, RWH, RWB and JTW researched data, contributed to data interpretation, and reviewed/ edited the manuscript. All authors reviewed and approved the final version of the manuscript. RWB is the guarantor of this work. 


\section{References}

1. Tamborlane WV, Sherwin RS, Genel M, Felig P (1979) Reduction to normal of plasma glucose in juvenile diabetes by subcutaneous administration of insulin with a portable infusion pump. N Engl $\mathrm{J}$ Med 300:573-578

2. The Diabetes Control and Complications Trial Research Group (1993) The effect of intensive treatment of diabetes on the development and progression of long-term complications in insulindependent diabetes mellitus. N Engl J Med 329:977-986

3. Sherr J, Cengiz E, Tamborlane WV (2009) From pumps to prevention: recent advances in the treatment of type 1 diabetes. Drug Discov Today 14:973-981

4. Johnson SR, Cooper MN, Jones TW, Davis EA (2013) Long-term outcome of insulin pump therapy in children with type 1 diabetes assessed in a large population-based case-control study. Diabetologia 56:2392-2400

5. Phillip M, Battelino T, Rodriguez $\mathrm{H}$ et al (2007) Use of insulin pump therapy in the pediatric age-group: consensus statement from the European Society for Paediatric Endocrinology, the Lawson Wilkins Pediatric Endocrine Society, and the International Society for Pediatric and Adolescent Diabetes, endorsed by the American Diabetes Association and the European Association for the Study of Diabetes. Diabetes Care 30:1653-1662
6. Maahs DM, Hermann JM, Holman N et al (2015) Rates of diabetic ketoacidosis: international comparison with 49,859 pediatric patients with type 1 diabetes from England, Wales, the U.S., Austria, and Germany. Diabetes Care 38:1876-1882

7. The Diabetes Control and Complications Trial Research Group (1994) Effect of intensive diabetes treatment on the development and progression of long-term complications in adolescents with insulin-dependent diabetes mellitus: Diabetes Control and Complications Trial. J Pediatr 125:177-188

8. Rewers MJ, Pillay K, de Beaufort C et al (2014) Assessment and monitoring of glycemic control in children and adolescents with diabetes. Pediatr Diabetes 15(Suppl 20):102-114

9. Chiang JL, Kirkman MS, Laffel LM, Peters AL, Type 1 Diabetes Sourcebook Authors (2014) Type 1 diabetes through the life span: a position statement of the American Diabetes Association. Diabetes Care 37:2034-2054

10. National Institute for Health and Care Excellence (2004) NICE guidelines [CG15]. Type 1 diabetes: diagnosis and management in children, young people, and adults. https://www.nice.org.uk/ guidance/cg15, accessed 6 October 2015

11. National Institute for Health and Care Excellence (2008) NICE technology appraisal guidance [TA151]. Continuous subcutaneous insulin infusion for the treatment of diabetes mellitus. https://www. nice.org.uk/guidance/ta151, accessed 6 October 2015 